Check for updates

Cite this: RSC Adv., 2017, 7, 29255

Received 30th March 2017 Accepted 7th May 2017

DOI: $10.1039 / c 7 r a 03660 d$

rsc.li/rsc-advances

\section{Factors affecting formation of deethyl and deisopropyl products from atrazine degradation in $\mathrm{UV} / \mathrm{H}_{2} \mathrm{O}_{2}$ and UV/PDS}

\author{
Congwei Luo, ${ }^{a}$ Jin Jiang, (D) *a Chaoting Guan, ${ }^{a}$ Jun Ma, ${ }^{\text {*a }}$ Suyan Pang, ${ }^{\mathrm{b}}$ Yang Song, ${ }^{\mathrm{a}}$ \\ Yi Yang, ${ }^{a}$ Jianqiao Zhang, ${ }^{\mathrm{C}}$ Daoji $\mathrm{Wu}^{\mathrm{d}}$ and Yinghong Guan ${ }^{\mathrm{e}}$
}

In this study, the formation of deethyl products (DEPs) (i.e., atrazine amide (Atra-imine) and deethylatrazine (DEA)) and deisopropyl product (i.e., deisopropylatrazine (DIA)) from parent atrazine (ATZ) degraded in UV/ $\mathrm{H}_{2} \mathrm{O}_{2}$ and UV/PDS processes under various conditions was monitored. It was found that $\mathrm{SO}_{4}{ }^{\cdot-}$ displayed a more distinctive preference to the ethyl function group of ATZ than $\mathrm{HO}$; leading to the higher ratio of DEPs/DIA in UV/PDS system than that in UV/ $\mathrm{H}_{2} \mathrm{O}_{2}$ system in pure water. The effects of water matrices (i.e., natural organic matter (NOM), carbonate/bicarbonate $\left(\mathrm{HCO}_{3}{ }^{-} / \mathrm{CO}_{3}{ }^{2-}\right)$, and chloride ions $\left.\left(\mathrm{Cl}^{-}\right)\right)$on ATZ degradation as well as formation of DEPs and DIA were evaluated in detail. The degradation of ATZ by UV/PDS was significantly inhibited in the presence of $\mathrm{NOM}, \mathrm{HCO}_{3}{ }^{-} / \mathrm{CO}_{3}{ }^{2-}$ or $\mathrm{Cl}^{-}$, because these components could competitively react with $\mathrm{SO}_{4}{ }^{-}$and/or $\mathrm{HO}$ to generate lower reactive secondary radicals (i.e., organic radicals, carbonate radicals $\left(\mathrm{CO}_{3}{ }^{-}\right)$or reactive chlorine radicals $(\mathrm{RCs})$ ). The yields of these DEPs and DIA products from ATZ degradation were not impacted by $\mathrm{NOM}$ or $\mathrm{HCO}_{3}{ }^{-} / \mathrm{CO}_{3}{ }^{2-}$, possibly due to the low reactivity of organic radicals and $\mathrm{CO}_{3}{ }^{--}$toward the side groups of ATZ. Howbeit, the increase of DIA yield companied with the decrease of DEPs yield was interestingly observed in the presence of $\mathrm{Cl}^{-}$, which was attributed to the promotion of $\mathrm{Cl}^{-}$at moderate concentration (mM range) for the conversion of $\mathrm{SO}_{4}{ }^{-}$into $\mathrm{HO}$. Comparatively, in the $\mathrm{UV} / \mathrm{H}_{2} \mathrm{O}_{2}$ process, $\mathrm{NOM}$ and $\mathrm{HCO}_{3}{ }^{-} / \mathrm{CO}_{3}{ }^{2-}$ exhibited a similar inhibitory effect on ATZ degradation, while the influence of $\mathrm{Cl}^{-}$was negligible. Differing from UV/PDS system, all these factors did not change DEPs and DIA yields in UV/ $\mathrm{H}_{2} \mathrm{O}_{2}$ process. Moreover, it was confirmed that RCs had a greater selectivity but a lower reactivity on attacking the ethyl function group than that of $\mathrm{SO}_{4}{ }^{\circ-}$. These findings were also confirmed by monitoring the degradation of ATZ as well as the formation of DEPs and DIA in three natural waters.

\section{Introduction}

Atrazine (6-chloro- $N$-ethyl- $N$ '-(1-methylethyl)-1,3,5-triazine-2,4diamine; ATZ), which has been most widely used as a synthetic herbicide to kill broadleaf weeds over the last half century, ${ }^{\mathbf{1 , 2}}$ has been frequently detected in ground and surface water. $^{2-4}$ Since many studies reported the high toxicity and endocrine disruption potentials of ATZ even at trace levels, the effective removal of ATZ in drinking water treatment has

${ }^{a}$ State Key Laboratory of Urban Water Resource and Environment, Harbin Institute of Technology, Harbin, 150090, China.E-mail: jiangjinhit@126.com; majun@hit.edu. cn; Fax: +86-451-86283010; Tel: +86-451-86283010

${ }^{b}$ Key Laboratory of Green Chemical Engineering and Technology of College of Heilongjiang Province, College of Chemical and Environmental Engineering, Harbin University of Science and Technology, Harbin 150040, China

${ }^{c}$ Luohu District Environment Protection and Water Affairs Bureau, China

${ }^{d}$ School of Municipal and Environmental Engineering, Shandong Jianzhu University, Jinan, 250010, China

${ }^{e}$ School of Water Conservancy and Civil Engineering, Northeast Agricultural University, Harbin 150040, China attracted great concerns in the protection of aquatic ecosystems. ${ }^{5}$ Numerous technologies have been developed to remove ATZ, including biological treatment, physical absorption, and chemical oxidation. ${ }^{6-10}$ Among these, chemical degradation has been generally recognized as a promising and decisive step.

Recently, advanced oxidation processes (AOPs) based on hydroxyl radicals $\left(\mathrm{HO}^{\circ}, E_{0}=1.89-2.72 \mathrm{~V} v s\right.$. NHE) and sulfate radicals $\left(\mathrm{SO}_{4}{ }^{-}, E_{0}=2.5-3.1 \mathrm{~V} v s\right.$. NHE $)$ have been of increasing interest as an option of ATZ degradation., ${ }^{\mathbf{1 1 1 , 1 2}}$ The reaction rates of these two radicals with ATZ have been reported to be similar and very fast (i.e., $\left.k=3.0 \times 10^{9} \mathrm{M}^{-1} \mathrm{~s}^{-1}\right) .{ }^{13,14}$ The effects of water matrices, including carbonate/bicarbonate $\left(\mathrm{CO}_{3}{ }^{2-} / \mathrm{HCO}_{3}{ }^{-}\right)$, chloride $\left(\mathrm{Cl}^{-}\right)$, and natural organic matters (NOM) on the degradation kinetics of ATZ in these AOPs have been evaluated as well. It has been suggested that these ubiquitous species can react with $\mathrm{HO}^{\circ}$ and/or $\mathrm{SO}_{4}{ }^{-}$- to different degrees, thus influencing the degradation rate of ATZ. For instance, it was reported that the presence of $\mathrm{CO}_{3}{ }^{2-} / \mathrm{HCO}_{3}{ }^{-}(>4 \mathrm{mM})$ inhibited ATZ oxidation by $\mathrm{HO}^{\cdot}$ and $\mathrm{SO}_{4}{ }^{-}-$generated from magnetic porous copper ferrite catalyzed peroxymonosulfate. ${ }^{15}$ In our previous 
study, it was found that $\mathrm{Cl}^{-}$over the concentration range of 0.5 to $10 \mathrm{mM}$ had a slight scavenging effect on ATZ removal in UV/ hydrogen peroxide $\left(\mathrm{UV} / \mathrm{H}_{2} \mathrm{O}_{2}\right)$ process but significantly suppressed the degradation of ATZ in UV/persulfate (UV/PDS) process. ${ }^{16}$ Additionally, ATZ was degraded more efficiently by $\mathrm{SO}_{4}{ }^{-}$than by $\mathrm{HO}^{\circ}$ in the presence of natural organic matter (NOM), which was attributed to the lower $\mathrm{SO}_{4}{ }^{-}$reaction rates with NOM than $\mathrm{HO}^{\cdot}\left(k_{\mathrm{SO}_{4}^{--}}{ }^{-\mathrm{ATZ}}=6.8 \times 10^{3} \mathrm{mg} \mathrm{C}^{-1} \mathrm{~s}^{-1} v s\right.$. $\left.k_{\mathrm{HO}, \mathrm{ATZ}}=1.4 \times 10^{4} \mathrm{mg} \mathrm{C}^{-1} \mathrm{~s}^{-1}\right) .{ }^{12}$

Moreover, the mechanisms of ATZ transformation in $\mathrm{HO}^{*}$ and/or $\mathrm{SO}_{4}{ }^{--}$based oxidation processes have been extensively investigated, ${ }^{6,17-19}$ and dealkylation is suggested as a preferred reaction pathway. ${ }^{20-23} \mathrm{HO}^{\circ}$ and/or $\mathrm{SO}_{4}{ }^{-}$abstract $\mathrm{H}$-atom from the carbon adjacent to nitrogen to produce a carbon-centered radical intermediate, and the addition of $\mathrm{O}_{2}$ to this intermediate results in generation of a peroxide radical. Then, followed by the loss of perhydroxyl radical, atrazine amide (Atra-imine) can be produced, and its subsequent hydrolysis leads to the formation of deethylatrazine (DEA). ${ }^{1}$ A similar mechanism is expected for the formation of simazine amide and its hydrolysis product deisopropylatrazine (DIA). The hydrolysis of simazine amide is much faster than Atra-imine. ${ }^{24}$ In addition, another two pathways including alkyl chain oxidation and dechlorinationhydroxylation can also occur during ATZ oxidation. ${ }^{25}$

Further, the percentages of deethyl products (DEPs) and desisopropyl product (i.e., DIA) were calculated, and their total yields accounted for about $70 \%$ degradation of ATZ. ${ }^{\mathbf{1 , 2 6}}$ The total yield of DEPs was determined to be higher than the yield of DIA. For instance, the molar ratio of DEPs to DIA was calculated to be 3 in the case of $\mathrm{HO}^{\circ}$, while for $\mathrm{SO}_{4}{ }^{-}$it was $10 .^{12,27}$ The higher yield of DEPs than DIA is generally explained by the facts that: (i) the $\mathrm{N}-\mathrm{H}$ bond at the $\mathrm{N}$-ethyl group is more acidic than that the $N$-isopropyl group, and the deprotonation would occur more preferably at the $\mathrm{H}-\mathrm{N}$-ethyl site, ${ }^{\mathbf{1 2}}$ (ii) both DEPs and DIA are unstable toward the further attack of reactive radicals, and the rate constant for the reaction of $\mathrm{SO}_{4}{ }^{-}-$and/or $\mathrm{HO}^{\circ}$ with DIA was slightly higher than that with DEPs (i.e., a slightly faster consumption of DIA), ${ }^{12,27}$ and (iii) steric hindrance effect of isopropyl group is much more significant than that of ethyl group, thus limiting the formation of DIA. ${ }^{28}$

Generally, secondary reactive organic or inorganic radicals (e.g., carbonate radical $\mathrm{CO}_{3}{ }^{-}$), reactive chlorine radicals (RCs) can be generated by $\mathrm{HO}^{\cdot}$ and/or $\mathrm{SO}_{4}{ }^{-}$- reacting with these water matrices. ${ }^{29-31} \mathrm{CO}_{3}{ }^{-}$as a highly selective one-electron oxidant $\left(E_{0}=1.78 \mathrm{~V} v s\right.$. NHE) can oxidize some electron-rich compounds (e.g., S-containing organics, N-containing organics, and phenols) through electron transfer or hydrogen abstraction. ${ }^{32-34}$ Chlorine atoms $\left(\mathrm{Cl}^{\circ}, E_{0}=2.4 \mathrm{~V} v s\right.$. NHE) and dichloride radical $\left(\mathrm{Cl}_{2}{ }^{-}-, E_{0}=2.0 \mathrm{~V} v s\right.$. NHE) can also react with various organic compounds, and the pathways mainly involve one-electron oxidation, $\mathrm{H}$-abstraction, and addition to unsaturated $\mathrm{C}-\mathrm{C}$ bond. ${ }^{35,36}$ The steady-state concentrations of $\mathrm{CO}_{3}{ }^{-}$ and RCs have been estimated to be higher than those of $\mathrm{HO}^{*}$ and $\mathrm{SO}_{4}{ }^{-}$for both $\mathrm{UV} / \mathrm{H}_{2} \mathrm{O}_{2}$ and $\mathrm{UV} / \mathrm{PDS}$ processes in the presence of $\mathrm{CO}_{3}{ }^{2-} / \mathrm{HCO}_{3}{ }^{-}$and $\mathrm{Cl}^{-}$(mM range). ${ }^{33}$ In addition, previous studies have been reported that NOM as a photosensitizer can lead to the photochemical formation of various reactive intermediates such as singlet oxygen $\left({ }^{1} \mathrm{O}_{2}\right)$, peroxy radical (ROO*), and ${ }^{3} \mathrm{DOM}^{*}$ in direct UV photolysis, and these species are considerably reactive toward organic contaminants such as atenolol, carbamazepine, and glimepiride. ${ }^{37}$ In our previous work, the influence of water constituents (i.e., $\mathrm{HCO}_{3}{ }^{2-}$ / $\mathrm{CO}_{3}{ }^{2-}, \mathrm{Cl}^{-}$, and NOM) on ATZ degradation kinetics have been investigated, and these factors on the relative contributions of $\mathrm{HO}^{\circ}$ and $\mathrm{SO}_{4}{ }^{-}-$in UV/PDS and $\mathrm{UV} / \mathrm{H}_{2} \mathrm{O}_{2}$ processes have been evaluated. ${ }^{16}$ However, the effects of various water constituents on the formation of primary products (i.e., DEPs and DIA) from ATZ are still unknown.

The main objective of this study was to investigate the formation of primary dealkylation products (i.e., DEPs and DIA) along with the degradation of ATZ in UV/PDS and $\mathrm{UV} / \mathrm{H}_{2} \mathrm{O}_{2}$ processes in the absence $v s$. presence of various water constituents, including $\mathrm{HCO}_{3}{ }^{2-} / \mathrm{CO}_{3}{ }^{2-}, \mathrm{Cl}^{-}$, and NOM. Then the characteristics of secondary reactive radicals were evaluated by monitoring the changes of the molar ratio of DEPs to DIA. Furthermore, the formation of DEPs and DIA was also examined in three natural waters.

\section{Materials and methods}

\section{Reagents}

ATZ, DEA, DIA, potassium peroxodisulfate, nitrobenzene (NB), sodium carbonate, hypochlorite (HClO), and sodium chloride of analytical grade were purchased from Sigma-Aldrich Chemical Co. Ltd. (USA). Suwannee River Natural Organic Matter (SRNOM) was purchased from the International Humic Substances Society. $\mathrm{H}_{2} \mathrm{O}_{2}$ solution ( $\left.35 \% \mathrm{w} / \mathrm{w}\right)$, sodium hypochlorite, phosphate monobasic monohydrate, sodium phosphate dibasic, sodium thiosulfate were of analytical-reagent grade and purchased from Sinopharm Chemical Reagent Co., Ltd., China. Other chemicals were of analytical grade or better and used without further purification. Three real water samples were collected from Songhua River (SW) (China), drinking water plants (EW), and groundwater (GW), respectively. All of the three samples were filtered through $0.45 \mu \mathrm{m}$ glass fiber membranes (Whatman) prior to using. The water quality parameters of these samples were shown in Table 1. ATZ was spiked to the real water samples to prepare ATZ-containing water.

\section{Analytical methods}

ATZ, DEA, and DIA were analyzed using high performance liquid chromatography (HPLC) with Hitachi 5110 pump and 5420 UV detector (Hitachi Chromaster), and the separation was carried out with a symmetry C18 column $(4.6 \times 150 \mathrm{~mm}, 5 \mu \mathrm{m}$ particle size, Waters). For the mobile phase, various isocratic

Table 1 Water quality of the actual water

\begin{tabular}{lllll}
\hline & $\mathrm{pH}$ & TOC $\left(\mathrm{mg} \mathrm{L}^{-1}\right)$ & Alkalinity $(\mathrm{mM})$ & $\mathrm{Cl}^{-}(\mathrm{mM})$ \\
\hline SW & $7.6 \pm 0.02$ & 3.12 & 0.4 & 0.15 \\
GW & $7.9 \pm 0.02$ & 1.62 & 2.3 & 3.50 \\
EW & $6.8 \pm 0.02$ & 1.53 & 0.3 & 0.22
\end{tabular}




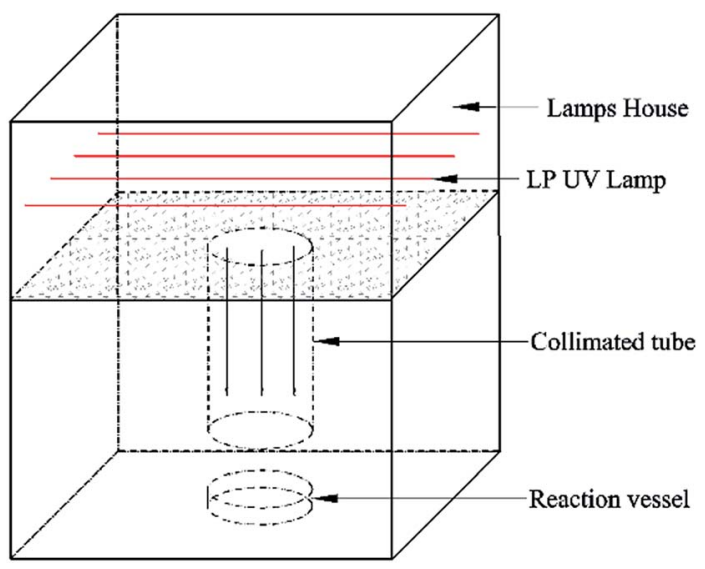

Fig. 1 The experimental device used for the UV photolysis experiments.

mixtures and gradients of $1 \%$ acetic acid and methanol were used. The flow rate was set at $1.0 \mathrm{~mL} \mathrm{~min}{ }^{-1}$, and the sample injection volume was $100 \mu \mathrm{L}$. The wavelengths of UV detection were set at $230 \mathrm{~nm}$ (ATZ), $260 \mathrm{~nm}$ (DEA), and $237 \mathrm{~nm}$ (DIA), respectively. ${ }^{23}$ PDS and $\mathrm{H}_{2} \mathrm{O}_{2}$ concentrations were measured by the iodometric method..$^{38}$ The stock solutions of residual chlorine and active chlorine were standardized by using the triiodide spectrophotometric method. ${ }^{39}$ NOM (mg C L ${ }^{-1}$ ) was measured with a Multi 3100 N/C TOC analyzer (Shimadzu).

\section{Experimental procedures}

The bench-scale UV irradiator equipped with four Low Pressure Hg UV lamps (254 nm, Heraeus, GPH212T5 L/4). $100 \mathrm{~mL}$ of solution with water depth of $4.0 \mathrm{~cm}$ was placed directly beneath the collimated tube for UV irradiation. The surface of the solution was approximately $30 \mathrm{~cm}$ from the UV lamp (Fig. 1). The irradiance of the UV irradiator was measured by a UV detector UVC radiometer (Photoelectric Instrument Factory of Beijing Normal University, Beijing, China) and calibrated following the suggestion of Bolton and Linden ${ }^{40}$ which was estimate to be $0.16 \mathrm{~mW} \mathrm{~cm}^{-2}$. All experiments were conducted at room temperature $\left(20^{\circ} \mathrm{C}\right)$. Phosphate buffer $(5 \mathrm{mM})$ was used to adjust $\mathrm{pH}$ value at 7.0. The samples were withdrawn at predetermined time intervals and immediately quenched using excess sodium sulfite. Then, they were kept at room temperature for $72 \mathrm{~h}$ in order to achieve complete conversion of Atraimine and simazine amide to DEA and DIA, respectively. Thus, the concentrations of initially formed deethyl products (DEPs) and deisopropyl products (DIPs) could be represented by the concentrations of DEA and DIA, respectively. ${ }^{1}$ All kinetic experiments were replicated independently at least three times, and the error bars represented the standard deviations.

\section{Results and discussion}

\section{Degradation of ATZ and formation of DIA and DEPs}

Fig. 2a showed the time courses of DEPs and DIA formation during ATZ oxidation in direct $\mathrm{UV}, \mathrm{UV} / \mathrm{H}_{2} \mathrm{O}_{2}$ and UV/PDS processes. As could be seen, the degradation rates of ATZ in $\mathrm{UV} / \mathrm{PDS}$ and $\mathrm{UV} / \mathrm{H}_{2} \mathrm{O}_{2}$ processes were much higher than that in direct UV process. DEPs and DIA were generated along with ATZ degradation in $\mathrm{UV} / \mathrm{PDS}$ and $\mathrm{UV} / \mathrm{H}_{2} \mathrm{O}_{2}$ processes, and then were completely depleted within the investigated time scales in the UV/PDS process. Comparatively, there were still residuals of the products after $60 \mathrm{~min}$ of reaction in the $\mathrm{UV} / \mathrm{H}_{2} \mathrm{O}_{2}$ process. For direct UV process, neither DEPs nor DIA was detected, which was consistent with the finding that hydroxylated atrazine rather than dealkylation products was the primary product of direct ATZ photolysis in previous study. ${ }^{41}$

The second-order rate constants of parent ATZ and its primary oxidation products (e.g. Atra-imine, DEA, DIA, terbuthylazine, and propazine) with $\mathrm{HO}^{\circ}$ and $\mathrm{SO}_{4}{ }^{--}$were comparable. ${ }^{12}$ Nevertheless, the higher molar extinction coefficient at $254 \mathrm{~nm}$ and the larger quantum efficiency of PDS $\left(21.1 \mathrm{M}^{-1}\right.$ $\mathrm{cm}^{-1}$ and $1.4 \mathrm{~mol}$ einstein $\left.{ }^{-1}\right)$ than those of $\mathrm{H}_{2} \mathrm{O}_{2}\left(18 \mathrm{M}^{-1} \mathrm{~cm}^{-1}\right.$ and $1.0 \mathrm{~mol}$ einstein ${ }^{-1}$ ) would result in higher steady-state concentrations of $\mathrm{SO}_{4}{ }^{--}$than $\mathrm{HO}^{\cdot 16}$. For instance, Lutze et al. reported that the concentration of $\mathrm{SO}_{4}{ }^{-{ }^{-}}$in UV/PDS process was 1.5-1.7 fold higher than that of $\mathrm{HO}^{\circ}$ in $\mathrm{UV} / \mathrm{H}_{2} \mathrm{O}_{2}$ process. ${ }^{42}$ These factors lead to the faster degradation of ATZ as well as DEPs and DIA in the UV/PDS process.

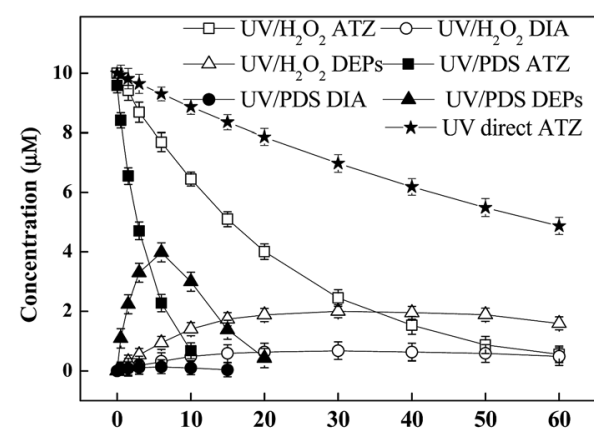

(a) Time (min)

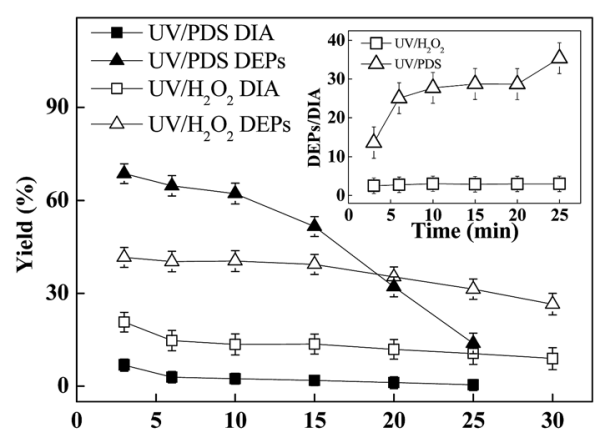

(b) Time (min)

Fig. 2 (a) Degradation of ATZ and formation of DEPs and DIA as a function of time in direct UV, UV/ $\mathrm{H}_{2} \mathrm{O}_{2}$, and UV/PDS processes. (b) Yields of DEPs and DIA as a function of time in UV/ $\mathrm{H}_{2} \mathrm{O}_{2}$ and UV/PDS processes. The insert showed the DEPs to DIA ratio. Experiment conditions: [ATZ] = $10 \mu \mathrm{M},\left[\mathrm{H}_{2} \mathrm{O}_{2}\right]=[\mathrm{PDS}]=1.5 \mathrm{mM}$, and $\mathrm{pH}=7$. 
In initial stage of ATZ reaction with $\mathrm{SO}_{4}{ }^{--}$(i.e., UV/PDS), the formation of DIA and DEPs accounted for approximate $7 \%$ and $75 \%$ of ATZ consumption, respectively, as shown in Fig. 2b. As for ATZ degradation by $\mathrm{HO}^{\circ}$, the initial yields of DIA and DEPs were $20 \%$ and $51 \%$, respectively. Accordingly, the DEPs to DIA ratio was calculated to be $>10$ in UV/PDS process, while it was $\approx 2.5$ in $\mathrm{UV} / \mathrm{H}_{2} \mathrm{O}_{2}$ process. This finding was consistent with previous reports, ${ }^{12,27,43}$ which could be attributed to that $\mathrm{SO}_{4}{ }^{\cdot-}$ displayed a more distinctive preference to the ethyl function group than $\mathrm{HO}^{\circ}$.

\section{Effect of $\mathrm{CO}_{3}{ }^{2-} / \mathrm{HCO}_{3}{ }^{-}$}

The effect of $\mathrm{CO}_{3}{ }^{2-} / \mathrm{HCO}_{3}{ }^{-}$on ATZ degradation as well as the formation of predominant products (i.e., DEPs and DIA) was investigated. It was observed that $\mathrm{CO}_{3}{ }^{2-} / \mathrm{HCO}_{3}{ }^{-}(5 \mathrm{mM})$ had a significant inhibitory effect on ATZ removal in both processes of UV/PDS and $\mathrm{UV} / \mathrm{H}_{2} \mathrm{O}_{2}$, and the efficiency of ATZ degradation in UV/PDS was still much higher than that in $\mathrm{UV} / \mathrm{H}_{2} \mathrm{O}_{2}$ (Fig. 3a). The negative effect of $\mathrm{CO}_{3}{ }^{2-} / \mathrm{HCO}_{3}{ }^{-}$on these two systems might result from the fact that significant amounts of $\mathrm{HO}^{\circ}$ and $\mathrm{SO}_{4}{ }^{--}$ could react with $\mathrm{CO}_{3}{ }^{2-} / \mathrm{HCO}_{3}{ }^{-}$to form the inorganic radical $\mathrm{CO}_{3}{ }^{--} .^{30}$ Previous studies have reported that $\mathrm{CO}_{3}{ }^{--}$presumably attacked on the site of the nitrogen atom of ATZ by electron transfer or hydrogen transfer, but it was much less reactive than $\mathrm{SO}_{4}{ }^{--}$or $\mathrm{HO}^{\circ}$, with a relatively low second order rate constant of $4 \times 10^{6} \mathrm{M}^{-1} \mathrm{~s}^{-1}$ (vs. $k_{\mathrm{SO}_{4}{ }^{-}, \mathrm{ATZ}}=3 \times 10^{9} \mathrm{M}^{-1} \mathrm{~s}^{-1}$ ). ${ }^{34}$

Further, results exhibited that the impact of $\mathrm{CO}_{3}{ }^{2-} / \mathrm{HCO}_{3}{ }^{-}$ on the formation of products (i.e., the concentrations of DEPS and DIA as well as the DEPs to DIA ratio) was relatively slight (Fig. 3b-d). Lutze et al. suggested that the reactivity of the side groups of ATZ (i.e., ethylamine and isopropylamine group) was comparable to ethanol and 2-propanol. ${ }^{12}$ The second order rates of $\mathrm{CO}_{3}{ }^{--}$plus 2-propanol and ethanol were $<4.0 \times 10^{4} \mathrm{M}^{-1} \mathrm{~s}^{-1}$ and $2.2 \times 10^{4} \mathrm{M}^{-1} \mathrm{~s}^{-1}$, respectively. ${ }^{44,45}$ This suggested the low reactive $\mathrm{CO}_{3}{ }^{-}$toward the side groups of ATZ was unable to impact the yields of DEPs and DIA.

\section{Effect of NOM}

As shown in Fig. 4a, the degradation of ATZ by UV/PDS or UV/ $\mathrm{H}_{2} \mathrm{O}_{2}$ was inhibited in the presence of NOM $\left(1 \mathrm{mg} \mathrm{C} \mathrm{L}^{-1}\right)$, and the former was still more efficient. Meanwhile, the degradation of generated DEPs and DIA was also significantly suppressed (Fig. 4b and c). Both yields of these two products as well as the DEPs to DIA ratio were not affected by NOM (Fig. $4 \mathrm{~b}$ and c inserts and Fig. 4d), similar to the case of $\mathrm{CO}_{3}{ }^{2-} / \mathrm{HCO}_{3}{ }^{-}$. The significant inhibition of NOM on ATZ and these two products degradation could be explained as following: (i) NOM usually acted as radical scavenger via competing for $\mathrm{HO}^{*}$ and $\mathrm{SO}_{4}{ }^{-}$ $\left(k_{\mathrm{HO}, \mathrm{NOM}}=1.4 \times 10^{4} \mathrm{~L} \mathrm{mg} \mathrm{C}^{-1}, k_{\mathrm{SO}_{4}{ }^{-}{ }^{-} \mathrm{NOM}}=6.8 \times 10^{3} \mathrm{~L} \mathrm{mg}\right.$ $\left.\mathrm{C}^{-1}\right) ;{ }^{12}$ (ii) NOM could exert an inner filter effect for the photolysis of oxidants. ${ }^{46}$ Previous studies reported that the reaction of $\mathrm{HO}^{\cdot}$ or $\mathrm{SO}_{4}{ }^{-}-$with organic matters (e.g., aromatic, aliphatic, ester, and ketone etc.) could yield organic radicals. Howbeit, the redox potentials of varied organic radicals (i.e., $-1.09 \mathrm{~V}$ to $+0.40 \mathrm{~V}$ ) have been determined in previous studies, ${ }^{47,48}$ which are much lower than those of $\mathrm{HO}^{\circ}$ and $\mathrm{SO}_{4}{ }^{\circ-}$. Thus, the yield of oxidation products could not be impacted by these organic radicals similar to $\mathrm{CO}_{3}{ }^{\circ-}$.

In addition, singlet oxygen $\left({ }^{1} \mathrm{O}_{2}\right)$, peroxy radical ( $\left.\mathrm{ROO}^{\circ}\right)$, and ${ }^{3} \mathrm{DOM}^{*}$ could be produced by direct photolysis of NOM as above mentioned. Minero et al. reported that the rate of ATZ photolysis was increased and the formation of dealkylation products

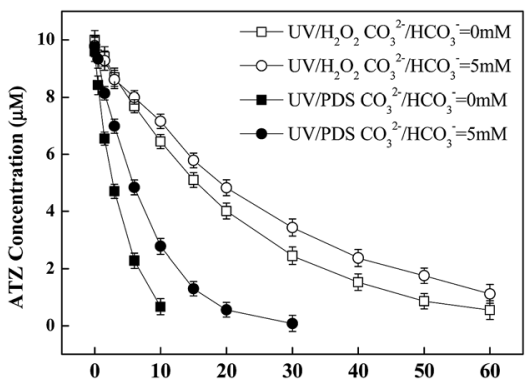

(a) Time (min)

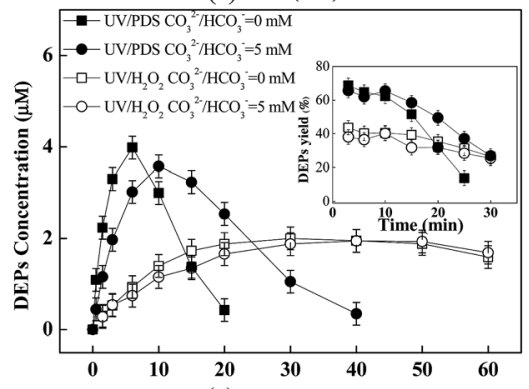

(c) Time (min)

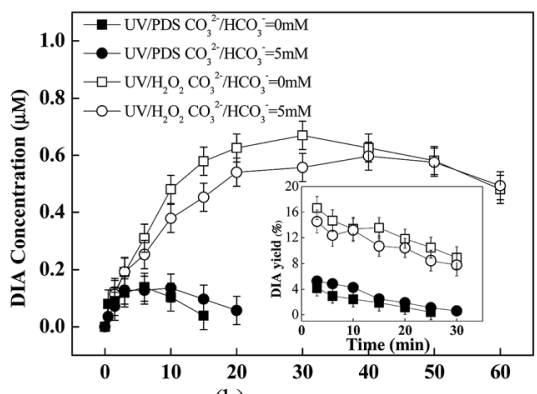

(b) Time (min)

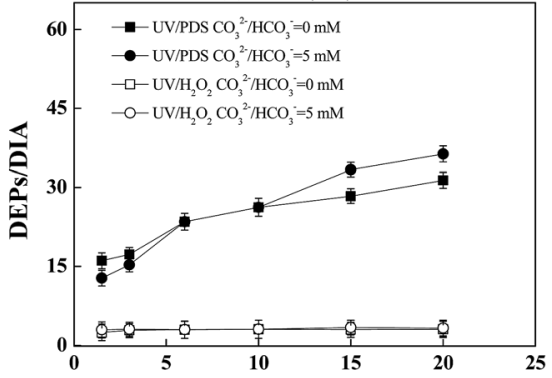

(d) Time (min)

Fig. 3 Effect of $\mathrm{CO}_{3}{ }^{2-} / \mathrm{HCO}_{3}{ }^{-}$on the degradation of ATZ (a), the formation of DIA (b), the formation of DEPs (c), and the DEPs to DIA ratio (d) as a function of time in $\mathrm{UV} / \mathrm{H}_{2} \mathrm{O}_{2}$ and UV/PDS processes. The inserts in (b) and (c) showed the effect of $\mathrm{CO}_{3}{ }^{2-} / \mathrm{HCO}_{3}{ }^{-}$on the yield of DEPs and DIA, respectively. Experiment conditions: $[\mathrm{ATZ}]=10 \mu \mathrm{M},\left[\mathrm{H}_{2} \mathrm{O}_{2}\right]=[\mathrm{PDS}]=1.5 \mathrm{mM}$, and $\mathrm{pH}=7$. 

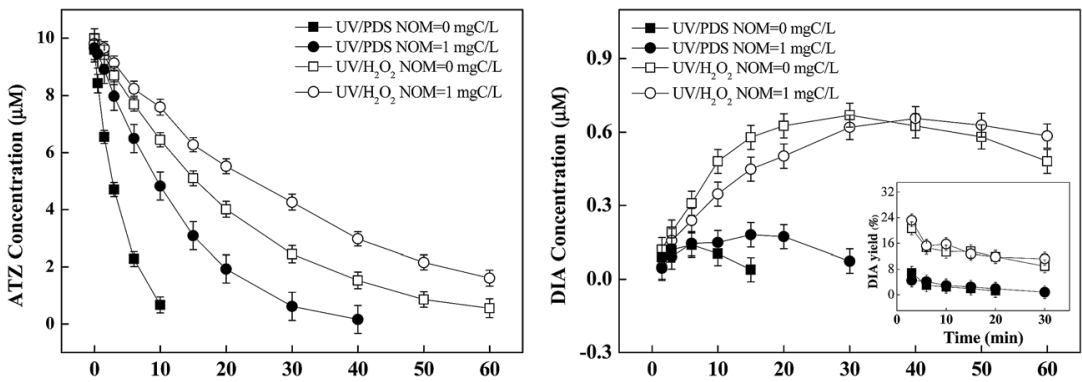

(a) Time (min)
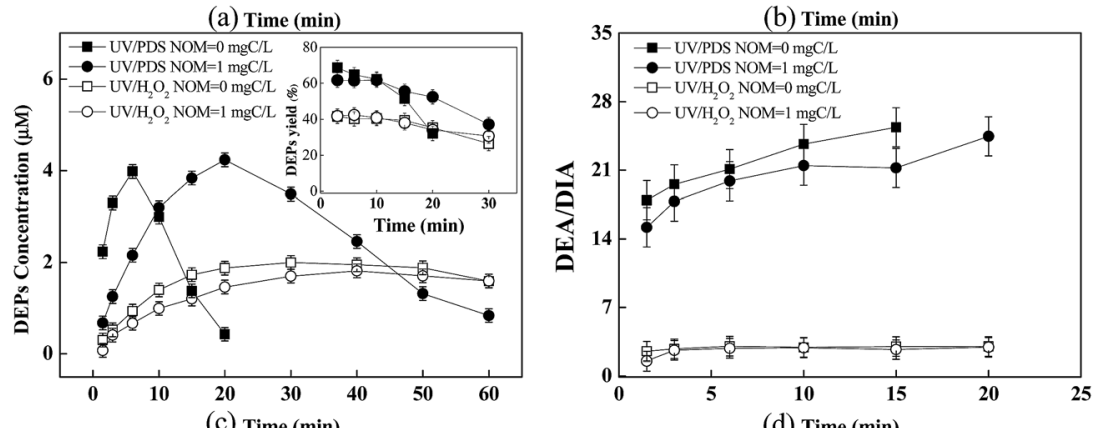

(d) Time (min)

Fig. 4 Effect of NOM on the degradation of ATZ (a), the formation of DIA (b), the formation of DEPs (c), and the DEPs to DIA ratio (d) as a function of time in UV/ $\mathrm{H}_{2} \mathrm{O}_{2}$ and UV/PDS processes. The inserts in (b) and (c) showed the effect of NOM on the yield of DEPs and DIA, respectively. Experiment conditions: $[\mathrm{ATZ}]=10 \mu \mathrm{M},\left[\mathrm{H}_{2} \mathrm{O}_{2}\right]=[\mathrm{PDS}]=1.5 \mathrm{mM}, \mathrm{NOM}=1 \mathrm{mg} \mathrm{C} \mathrm{L}^{-1}$, and $\mathrm{pH}=7$.

was enhanced in the presence of humic material, suggesting that NOM promoted the formation of various reactive intermediates in direct UV process. ${ }^{49}$ However, the result in this work indicated that the degradation of ATZ by direct photolysis was slightly inhibited in the presence of NOM, and no DEPs or DIA was detected (Fig. 5), consistent with Torrents' study. ${ }^{41}$ This discrepancy could be explained by the fact that different functional groups present in NOM could influence the photochemical reactions. ${ }^{37}$

\section{Effect of $\mathbf{C l}^{-}$}

Experiments were carried out in the presence of $\mathrm{Cl}^{-}(5 \mathrm{mM})$ to investigate its effect on ATZ degradation as well as the

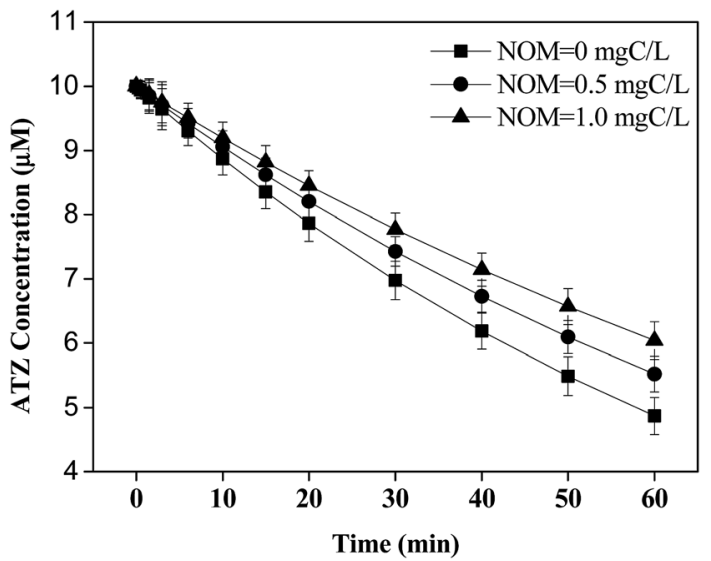

Fig. 5 Effect of NOM on the degradation of ATZ in UV direct process. Experiment conditions: [ATZ] $=10 \mu \mathrm{M}, \mathrm{pH}=7$. formation of DEPs and DIA. As shown in Fig. 6, $\mathrm{Cl}^{-}$had a negligible effect on the transformation of ATZ in $\mathrm{UV} / \mathrm{H}_{2} \mathrm{O}_{2}$ process, including the kinetics and products formation. However, the presence of $\mathrm{Cl}^{-}$inhibited ATZ degradation and significantly influenced the formation trend of DEPs and DIA in UV/PDS process.

It was observed that the initial yield of DIA increased from approximate $6.8-18.9 \%$ when $5 \mathrm{mM} \mathrm{Cl}^{-}$was present, while the initial yield of DEPs decreased from approximate $75-46.4 \%$ (Fig. 6b and c insets). Correspondingly, the initial ratio of DEPs to DIA decreased from 13.6 to 3.3. In $\mathrm{UV} / \mathrm{H}_{2} \mathrm{O}_{2}$ process, $\mathrm{Cl}^{-}$ scavenging for $\mathrm{HO}^{*}$ was apparently weak considering the fast backward reaction process (i.e., $6.1 \times 10^{9} \mathrm{~s}^{-1}$ ) in the equilibrium reaction of $\mathrm{HO}^{*}$ with $\mathrm{Cl}^{-}$to form $\mathrm{ClOH}^{-\cdot, 50,51}$ which explained no impact of $\mathrm{Cl}^{-}$on ATZ degradation. In contrast, the significant inhibitory effect of $\mathrm{Cl}^{-}$on ATZ oxidation by UV/PDS could be attributed to the much higher second-order rate constant of $\mathrm{Cl}^{-}$reacting with $\mathrm{SO}_{4}{ }^{-}$(i.e., $3.0 \times 10^{8} \mathrm{M}^{-1} \mathrm{~s}^{-1}$ ) than that of $\mathrm{HO}^{*}$ (i.e., $1.8 \times 10^{5} \mathrm{M}^{-1} \mathrm{~s}^{-1}$ ) at neutral $\mathrm{pH}^{.2}$

It was well-known that $\mathrm{Cl}^{-}$could be oxidized by $\mathrm{SO}_{4}{ }^{-}$to form reactive RCs such as $\mathrm{Cl}^{\circ}, \mathrm{ClO}^{\circ}$ and $\mathrm{Cl}_{2}{ }^{-} \cdot{ }^{53}$ Recent studies reported that RCs were responsible for the degradation of certain organic pollutants (e.g., $\quad N, N$-diethyl-3methylbenzamide, caffeine, trimethoprim, and acid orange 7). ${ }^{50,54}$ In order to clarify the pattern of DEPs and DIA formation during the reaction of RCs with ATZ, UV/HClO, a typical process of generating RCs, was employed for oxidation of ATZ. NB was used herein as an effective quencher for $\mathrm{HO}^{*}\left(k_{\mathrm{NB}, \mathrm{HO}}=6.0 \times\right.$ $\left.10^{8} \mathrm{M}^{-1} \mathrm{~s}^{-1}\right)$, but not for RCs $\left(<10^{6} \mathrm{M}^{-1} \mathrm{~s}^{-1}\right)\left(\right.$ e.g., $\mathrm{Cl}^{\circ}, \mathrm{ClO}^{\circ}$ and $\left.\mathrm{Cl}_{2}{ }^{\cdot-}\right){ }^{53,55-57}$ As shown in Fig. 7, ATZ was effectively oxidized in $\mathrm{UV} / \mathrm{HClO}$ process, and the initial yields of DIA and DEPs were 

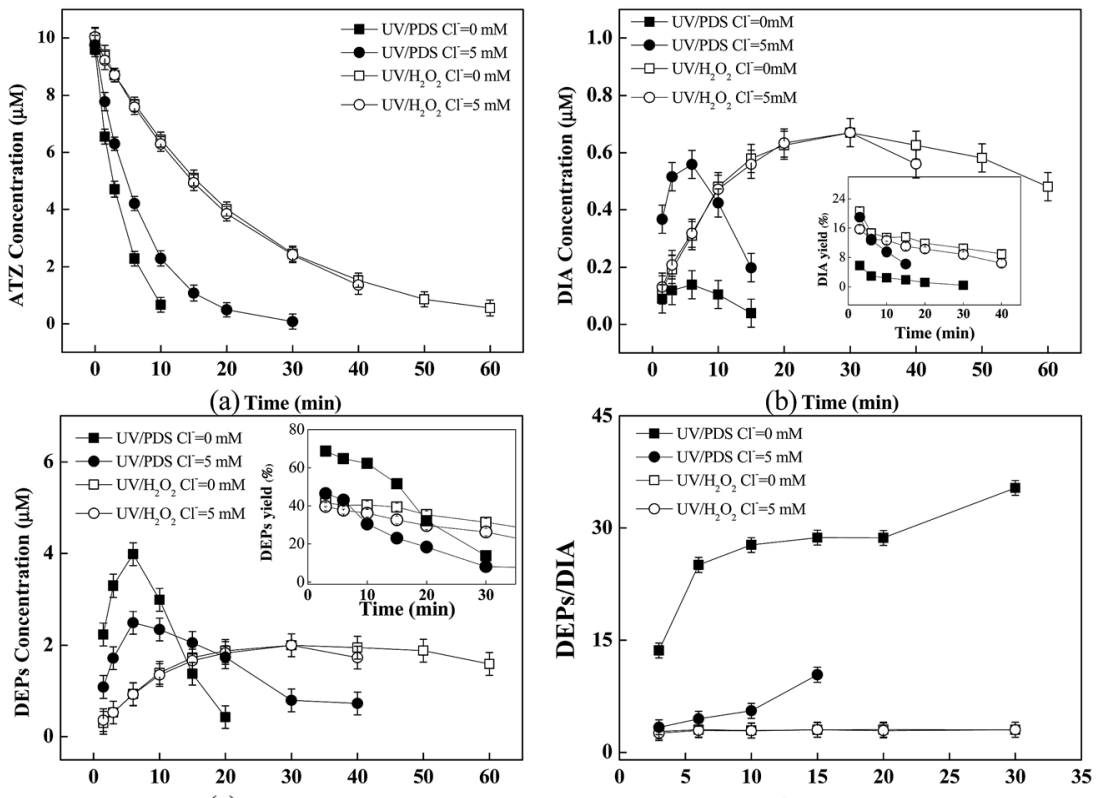

(d) Time (min)

Fig. 6 Effect of $\mathrm{Cl}^{-}$on the degradation of ATZ (a), the formation of DIA (b), the formation of DEPs (c), and the DEPs to DIA ratio (d) as a function of time in UV/ $\mathrm{H}_{2} \mathrm{O}_{2}$ and UV/PDS processes. The inserts in (b) and (c) showed the effect of $\mathrm{Cl}^{-}$on the yield of DEPs and DIA, respectively. Experiment conditions: $[\mathrm{ATZ}]=10 \mu \mathrm{M},\left[\mathrm{H}_{2} \mathrm{O}_{2}\right]=[\mathrm{PDS}]=1.5 \mathrm{mM}, \mathrm{Cl}^{-}=5 \mathrm{mM}$, and $\mathrm{pH}=7$.

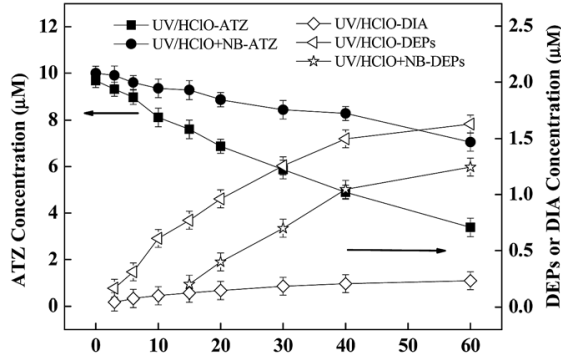

(a) Time (min)

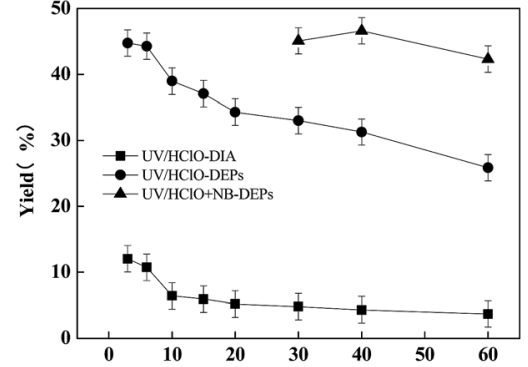

(b) Time( min)

Fig. 7 (a) Degradation of ATZ and formation of DEPs and DIA as a function of time in UV/HCIO process. (b) Yields of DEPs and DIA as a function of time in UV/HClO process. $\mathrm{HClO}=1.5 \mathrm{mM}, \mathrm{ATZ}=10 \mu \mathrm{M}, \mathrm{NB}=100 \mu \mathrm{M}$, and $\mathrm{pH}=7$.

approximately $12 \%$ and $45 \%$, respectively. Hence, the DEPs to DIA ratio could be calculated to be $\approx 4$ (Fig. 7b). The coexistence of NB significantly inhibited the degradation of ATZ, as expected. It was noteworthy that the yield of DEPs was about $45 \%$ but no DIA was detected in the presence of NB, suggesting that RCs had a great selectivity on attacking the ethylamine group of ATZ to form DEPs. Accordingly, it seemed likely that the promoted yield of DIA in the UV/PDS process in the presence of $\mathrm{Cl}^{-}$could not be attributed to the generation of RCs.

Actually, in the literature one could find an important conclusion on the influence of $\mathrm{Cl}^{-}$on $\mathrm{SO}_{4}{ }^{-}$based oxidation, $\mathrm{Cl}^{-}$could turn $\mathrm{SO}_{4}{ }^{-}$into $\mathrm{HO}^{\cdot}$ at $\mathrm{pH} \geq 7$. Zhang et al. investigated the effect of $\mathrm{Cl}^{-}$on pharmaceuticals degradation in UV/ PDS process, and obtained that the steady-state concentration of $\mathrm{HO}^{\circ}$ increased from $1.75 \times 10^{-13} \mathrm{M}$ to $2.78 \times 10^{-11} \mathrm{M}$ due to the addition of $0.1 \mathrm{M} \mathrm{Cl}^{-}$by kinetic modeling. ${ }^{58}$ Lutze et al. suggested that the ratio of degradation rates of 4-nitrobenzoic acid (pNBA) vs. 4-chlorobenzonic acid (pCBA) could be used as an indicator for the transformation of $\mathrm{SO}_{4}{ }^{-}$to $\mathrm{HO}^{\circ}$ in the UV/ PDS with $\mathrm{Cl}^{-} . .^{22}$ It was found that the slope $\left(\ln C / C_{0}\right.$ (pNBA) $v s$. In $C / C_{0}$ (pCBA)) for UV/PDS in presence of $\mathrm{Cl}^{-}$was equal to the $\mathrm{UV} / \mathrm{H}_{2} \mathrm{O}_{2}$ without $\mathrm{Cl}^{-}$present, indicating $\mathrm{HO}^{\bullet}$ were the major reactive species in both processes. In this study, the initial ratio of DEPs to DIA in the presence of $\mathrm{Cl}^{-}$in UV/PDS process (i.e., 3) was very close to that in $\mathrm{UV} / \mathrm{H}_{2} \mathrm{O}_{2}$ process (i.e., 2.5), which provided further evidence for the facilitated effect of $\mathrm{Cl}^{-}$on the transformation of $\mathrm{SO}_{4}{ }^{-}$to $\mathrm{HO}^{\circ}$.

\section{Degradation of atrazine under natural water background}

The degradation of ATZ as well as the formation of DEPs and DIA in three natural waters were investigated. As could be seen in Fig. 8a, UV/PDS system was more effective than $\mathrm{UV} / \mathrm{H}_{2} \mathrm{O}_{2}$ system under the identical conditions. This was ascribed to that the quantum efficiency for photolysis and the molar extinction 

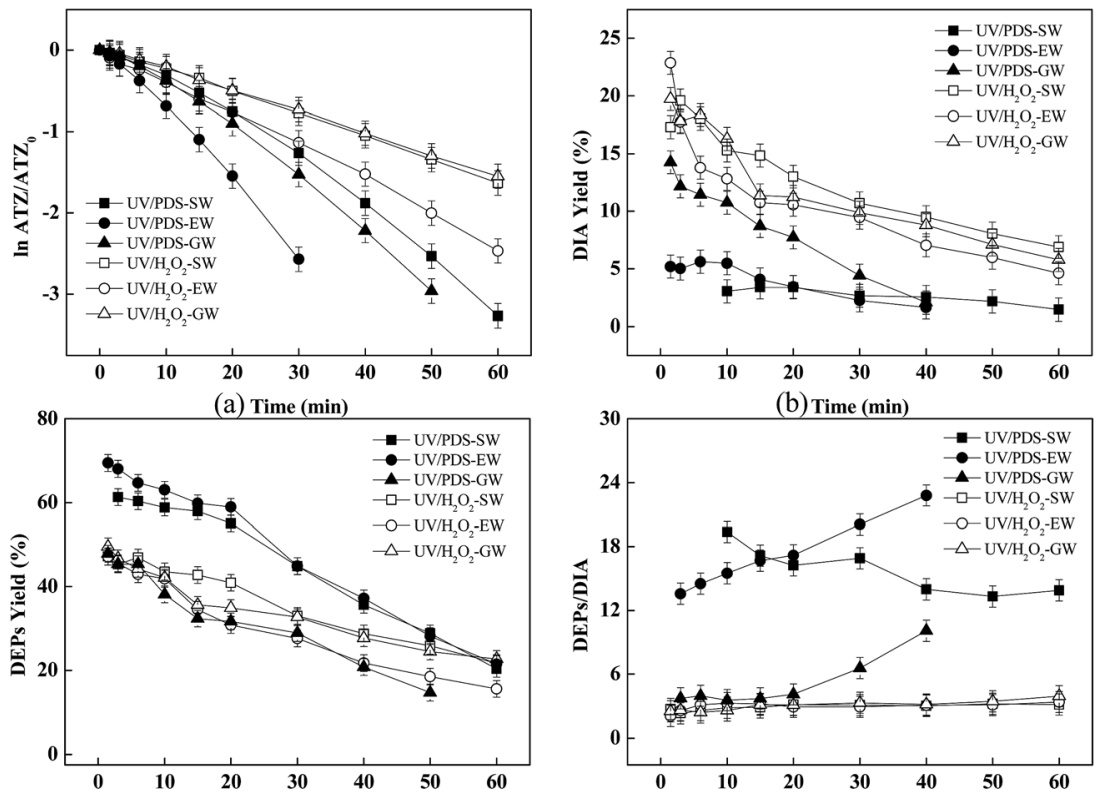

(c) Time (min)

(d) Time (min)

Fig. 8 The degradation of ATZ (a), the formation of DIA (b), the formation of DEPs (c), and the DEPs to DIA ratio (d) as a function of time in UV/ $\mathrm{H}_{2} \mathrm{O}_{2}$ and UV/PDS processes in actual waters. Experiment conditions: [ATZ] $=10 \mu \mathrm{M},\left[\mathrm{H}_{2} \mathrm{O}_{2}\right]=[P D S]=1.5 \mathrm{mM}$, and $\mathrm{pH}=7$.

coefficient for $\mathrm{S}_{2} \mathrm{O}_{8}{ }^{2-}$ were higher than $\mathrm{H}_{2} \mathrm{O}_{2}$, as described above. The yields of DIA and DEPs in these three natural waters were fairly close in $\mathrm{UV} / \mathrm{H}_{2} \mathrm{O}_{2}$ system. Distinguishingly, the yield of DIA in UV/PDS system in the effluent from GW was much higher than those in effluents from SW and EW, and meanwhile the yield of DEPs showed the reverse change trend. As shown in Fig. $8 \mathrm{~b}$ and $\mathrm{c}$, the initial yields of DIA and DEPs were about $15 \%$ and $50 \%$ in GW during UV/PDS process, respectively, while the initial yields of DIA and DEPs were approximately $5 \%$ and $65 \%$ in SW or EW, respectively. This could be attributed to the higher concentration of $\mathrm{Cl}^{-}$in GW than that in SW and EW (Table 1), and this further confirmed that $\mathrm{Cl}^{-}$played an important role in the transformation of reactive oxidative species as well as the yields of ATZ oxidation products.

\section{Conclusion}

The formation of DEPs and DIA was investigated in $\mathrm{UV} / \mathrm{H}_{2} \mathrm{O}_{2}$ and UV/PDS processes under various conditions. For all studied processes the following conclusions were obtained:

(i) UV/PDS system was more effective than $\mathrm{UV} / \mathrm{H}_{2} \mathrm{O}_{2}$ system for the degradation of ATZ and its oxidation products under the same conditions.

(ii) $\mathrm{SO}_{4}{ }^{--}$displayed a more distinctive preference to the ethyl function group than $\mathrm{HO}^{\circ}$, leading to the higher ratio of DEPs/ DIA in UV/PDS system than $\mathrm{UV} / \mathrm{H}_{2} \mathrm{O}_{2}$ system in pure water.

(iii) $\mathrm{CO}_{3}{ }^{2-} / \mathrm{HCO}_{3}{ }^{-}$and NOM had a certain inhibitory effect on ATZ degradation in both UV/PDS and $\mathrm{UV} / \mathrm{H}_{2} \mathrm{O}_{2}$ processes, due to their competition on $\mathrm{SO}_{4}{ }^{--}$and/or $\mathrm{HO}^{\circ}$. The generated $\mathrm{CO}_{3}{ }^{-}$and organic radicals had very low reactivity toward ATZ as well as its side groups, and thus they showed a negligible effect on the yields of DEPs and DIA. (iv) $\mathrm{Cl}^{-}$suppressed the degradation of ATZ in UV/PDS, but had a slight effect on that in $\mathrm{UV} / \mathrm{H}_{2} \mathrm{O}_{2}$. The decrease of DEPs concentration and the increase of DIA concentration in UV/PDS process were observed when a certain concentration of $\mathrm{Cl}^{-}$was present, attributed to that $\mathrm{Cl}^{-}$enhanced the transformation of $\mathrm{SO}_{4}{ }^{-{ }^{-}}$into $\mathrm{HO}^{*}$. In addition, $\mathrm{RCs}\left(\right.$ i.e., $\mathrm{Cl}^{\circ}, \mathrm{ClO}^{\circ}$ and $\mathrm{Cl}_{2}{ }^{-}$) were found to be more selective on attacking the ethylamine group of ATZ.

\section{Acknowledgements}

This work was financially supported by the National Natural Science Foundation of China (51578203 and 51408107), the Funds of the State Key Laboratory of Urban Water Resource and Environment (HIT, 2016DX13), the Foundation for the Author of National Excellent Doctoral Dissertation of China (201346), the National Key Research and Development Program (2016YFC0401107), and the Heilongjiang Province Postdoctoral Science Foundation (LBH-Q15057).

\section{References}

1 J. L. Acero, K. Stemmler and U. von Gunten, Environ. Sci. Technol., 2000, 34, 591-597.

2 E. Pelizzrtti, V. Maurino, C. Minero, V. Carlin, E. Pramauro, O. Zerbinati and M. L. Tosato, Environ. Sci. Technol., 1990, 24, 1559-1565.

3 W. Hua, E. R. Bennett and R. J. Letcher, Water Res., 2006, 40, 2259-2266.

4 H. R. Buser, Environ. Sci. Technol., 1990, 24, 1049-1058.

5 C. Sulmon, F. Ramel, G. Gouesbet and I. Couée, Environ. Sci. Technol., 2014, 48, 6055-6056. 
6 N. C. Meakins, J. M. Bubb and J. N. Lester, Chemosphere, 1994, 28, 1611-1622.

7 S. R. D. Solla and P. A. Martin, Chemosphere, 2011, 85, 820825.

8 X. Kong, J. Jiang, J. Ma, Y. Yang, W. Liu and Y. Liu, Water Res., 2015, 90, 15-23.

9 S. Komtchou, A. Dirany, P. Drogui, N. Delegan, M. A. E. Khakani, D. Robert and P. Lafrance, Chemosphere, 2016, 157, 79-88.

10 L. Xu, H. Zang, Q. Zhang, Y. Chen, Y. Wei, J. Yan and Y. Zhao, Chem. Eng. J., 2013, 232, 174-182.

11 Y. Yang, J. Jiang, X. Lu, J. Ma and Y. Liu, Environ. Sci. Technol., 2015, 49, 7330-7339.

12 H. V. Lutze, S. Bircher, I. Rapp, N. Kerlin, R. Bakkour, M. Geisler, C. von Sonntag and T. C. Schmidt, Environ. Sci. Technol., 2015, 49, 1673-1680.

13 M. Cheng, G. Zeng, D. Huang, C. Lai, P. Xu, C. Zhang, Y. Liu, J. Wan, X. Gong and Y. Zhu, J. Hazard. Mater., 2016, 312, 184191.

14 J. A. Khan, X. He, H. M. Khan, N. S. Shah and D. D. Dionysiou, Chem. Eng. J., 2013, 218, 376-383.

15 Y. H. Guan, J. Ma, Y. M. Ren, Y. Z. Liu, J. Xiao, L. Lin and C. Zhang, Water Res., 2013, 47, 5431-5438.

16 C. W. Luo, J. Ma, J. Jiang, Y. Z. Liu, Y. Song, Y. Yang, Y. H. Guan and D. J. Wu, Water Res., 2015, 80, 99-108.

17 J. A. Khan, X. He, H. M. Khan, N. S. Shah and D. D. Dionysiou, Chem. Eng. J., 2013, 218, 376-383.

18 S. M. Arnold, W. J. Hickey and R. F. Harris, Environ. Sci. Technol., 1995, 29, 2083-2089.

19 F. J. Beltrán, G. Ovejero and B. Acedo, Water Res., 1993, 27, 1013-1021.

20 S. K. Papiernik and R. F. Spalding, J. Agric. Food Chem., 1998, 46, 749-754.

21 E. M. Thurman, M. T. Meyer, M. S. Mills, L. R. Zimmerman, C. A. Perry and D. A. Goolsby, Environ. Sci. Technol., 1994, 28, 2267-2277.

22 F. J. Beltran, M. Gonzalez, F. J. Rivas and P. Alvarez, Environ. Toxicol. Chem., 1996, 15, 868-872.

23 B. D. Amaral, J. A. de Araujo, P. G. Peralta-Zamora and N. Nagata, Microchem. J., 2014, 117, 262-267.

24 Y. Ji, C. Dong, D. Kong and J. Lu, J. Hazard. Mater., 2015, 285, 491-500.

25 Y. Ji, C. Dong, D. Kong, J. Lu and Q. Zhou, Chem. Eng. J., 2015, 263, 45-54.

26 C. L. Bianchi, C. Pirola, V. Ragaini and E. Selli, Appl. Catal., B, 2006, 64, 131-138.

27 A. Tauber and C. V. Sonntag, Acta Hydrochim. Hydrobiol., 2000, 28, 15-23.

28 M. Alipour, Chem. Phys., 2014, 434, 11-14.

29 Y. Xu, Z. Lin and H. Zhang, Chem. Eng. J., 2016, 285, 392-401.

30 R. Zhang, P. Sun, T. H. Boyer, L. Zhao and C. Huang, Environ. Sci. Technol., 2015, 49, 3056-3066.
31 A. A. Presto, K. E. Huff Hartz and N. M. Donahue, Environ. Sci. Technol., 2005, 39, 7036-7045.

32 S. Canonica, T. Kohn, M. Mac, F. J. Real, J. Wirz and U. von Gunten, Environ. Sci. Technol., 2005, 39, 9182-9188.

33 J. P. Huang and S. A. Mabury, Environ. Toxicol. Chem., 2000, 19, 2181-2188.

34 J. Huang and S. A. Mabury, Environ. Toxicol. Chem., 2000, 19, 1501-1507.

35 J. Fang, Y. Fu and C. Shang, Environ. Sci. Technol., 2014, 48, 1859-1868.

36 Z. Wu, J. Fang, Y. Xiang, C. Shang, X. Li, F. Meng and X. Yang, Water Res., 2016, 104, 272-282.

37 E. Lee, H. K. Shon and J. Cho, J. Hazard. Mater., 2014, 276, 19.

38 N. A. Frigerio, Anal. Chem., 1963, 35, 412-413.

39 W. Li, T. Jain, K. Ishida and H. Liu, Environ. Sci.: Water Res. Technol., 2017, 3, 128-138.

40 J. R. Bolton and K. G. Linden, J. Environ. Eng., 2003, 129, 209215.

41 A. Torrents, B. G. Anderson, S. Bilboulian, W. E. Johnson and C. J. Hapeman, Environ. Sci. Technol., 1997, 31, 1476-1482.

42 H. V. Lutze, N. Kerlin and T. C. Schmidt, Water Res., 2015, 72, 349-360.

43 A. Tauber and C. von Sonntag, Acta Hydrochim. Hydrobiol., 2000, 28, 15-23.

44 Y. Liu, X. He, X. Duan, Y. Fu and D. D. Dionysiou, Chem. Eng. J., 2015, 276, 113-121.

45 S. Canonica, T. Kohn, M. Mac, F. J. Real, J. Wirz and U. von Gunten, Environ. Sci. Technol., 2005, 39, 9182-9188.

46 J. Brame, M. Long, Q. Li and P. Alvarez, Water Res., 2014, 60, 259-266.

47 P. S. Rao and E. Hayon, J. Am. Chem. Soc., 1974, 96, 12871294.

48 S. Bank and D. A. Juckett, J. Am. Chem. Soc., 1976, 24, 77427746.

49 C. Minero, E. Pramauro, E. Pelizzetti, M. Dolci and A. Marchesini, Chemosphere, 1992, 24, 1597-1606.

50 P. Sun, W. Lee, R. Zhang and C. Huang, Environ. Sci. Technol., 2016, 50(24), 13265-13273.

51 X. Lou, D. Xiao, C. Fang, Z. Wang, J. Liu, Y. Guo and S. Lu, Environ. Sci. Pollut. Res., 2016, 23, 4778-4785.

52 T. N. Das, J. Phys. Chem. A, 2001, 105, 9142-9155.

53 Z. Wu, J. Fang, Y. Xiang, C. Shang, X. Li, F. Meng and X. Yang, Water Res., 2016, 104, 272-282.

54 R. Yuan, Z. Wang, Y. Hu, B. Wang and S. Gao, Chemosphere, 2014, 109, 106-112.

55 Y. Xiang, J. Fang and C. Shang, Water Res., 2016, 90, 301-308. 56 M. J. Watts and K. G. Linden, Water Res., 2007, 41, 28712878.

57 J. Fang, Y. Fu and C. Shang, Environ. Sci. Technol., 2014, 48, 1859-1868.

58 R. Zhang, P. Sun, T. H. Boyer, L. Zhao and C. Huang, Environ. Sci. Technol., 2015, 49, 3056-3066. 